\title{
COMPARATIVE COST-BASED ANALYSIS OF A NOVEL PLUG-IN HYBRID ELECTRIC VEHICLE WITH CONVENTIONAL AND HYBRID ELECTRIC VEHICLES
}

\author{
A.R. Salisa ${ }^{1}$, P.D. Walker ${ }^{2}$, N. Zhang ${ }^{2}$ and J.G. Zhu ${ }^{2}$ \\ ${ }^{1}$ School of Ocean Engineering, Universiti Malaysia Terengganu \\ 21030 Kuala Terengganu, Terengganu Darul Iman, Malaysia \\ Phone : +609-6683447; Fax : +609-6683991 \\ Email: salisa@umt.edu.my \\ ${ }^{2}$ School of Electrical, Mechanical and Mechatronic Systems, \\ Faculty of Engineering and Information Technology \\ University of Technology, Sydney, \\ P. O. Box 123, Broadway, NSW 2007, Australia
}

\begin{abstract}
Hybrid electric vehicles provide higher fuel efficiency and lower emissions through the combination of the conventional internal combustion engine with electric machines. This paper analyzes and compares two types of hybrid electric powertrain with a conventional vehicle powertrain to study the lifetime costs of these vehicles. The novelty of the University of Technology Sydney plug-in hybrid electric vehicle (UTS PHEV) arises through a special power-splitting device and energy management strategy. The UTS PHEV and comparative powertrains are studied through numerical simulations to determine fuel consumption for the proposed low and high congestion drive cycles. Satisfactory results are achieved in terms of fuel economy, the all-electric range and electrical energy consumption for the UTS PHEV powertrain, providing significant improvement over the alternative powertrains. The analysis of these vehicles is extended to include a cost-based analysis of each powertrain in order to estimate the total lifetime costs at different fuel prices. The results obtained from this analysis demonstrate that whilst the conventional powertrain is cheaper in terms of purchase and maintenance costs, both alternative configurations are more cost-effective overall as the average price of fuel increases.
\end{abstract}

Keywords: Hybrid electric vehicles; energy management strategy; fuel economy; operation cost.

\section{INTRODUCTION}

Society's concern with oil depletion, global warming, fuel economy and more stringent vehicle emissions standards has led many automotive manufacturers to produce alternative energy vehicles, which are more fuel-efficient and environmentally friendly than internal combustion engine (ICE) powered vehicles but do not sacrifice drive comfort or performance. New types of clean and energy-efficient vehicle powertrains [1-3], such as electric vehicles (EVs), hybrid EVs (HEVs) [4, 5] and plug-in HEVs (PHEVs), boost the vehicle fuel economy and at the same time reduce emissions. However, the higher initial purchase price and battery replacement costs detract from these benefits, negatively influencing consumer acceptance. Pure EVs are the most 
energy-efficient of these alternative vehicles and are considered to produce zero emissions if the energy storage system (ESS) is recharged by electricity generated from clean energy sources. However, their range is limited by the energy density of the energy storage devices, which primarily include batteries, but also ultra-capacitors [6, 7]. Alternatively, HEVs can cover a much longer driving range than that of pure EVs through the use of onboard fuel storage with significantly less emission and fuel consumption than that of conventional ICE-powered vehicles. According to power flow, there are three types of conventional HEV powertrain configurations, namely series, parallel, and series-parallel [8]. Existing PHEVs and series-parallel HEVs contain two separate electric machines (EM) functioning as the electric motor or generator depending on driving requirements. This tends to increase the vehicle weight and cost, especially in the case of PHEV, with its larger requirements for electric drive and energy storage. A comparison of existing and proposed hybrid and electric vehicles in [9-11] indicates that larger energy storage in combination with electric and internal combustion powertrains significantly influences gross vehicle mass. By reducing the number of required EMs through the application of novel energy management strategies and power-splitting devices, the associated costs and weight can be reduced, such as in Abdul Rahman, Zhang [12].

To address several issues surrounding hybrid and electric vehicles a novel powertrain was presented in [13], and is referred to as the University of Technology Sydney PHEV (UTS PHEV). This powertrain takes advantage of a novel 4-speed automatic transmission (AT) without torque converter and a unique energy management strategy (EMS) to present a new powertrain which contains only one EM, operated as either an electric motor or a generator during different time intervals as specified by the EMS. The newly proposed AT enables the powertrain to operate in various modes available to series-parallel hybrid electric vehicles, including electric only, ICE only, and HEV modes. To improve the dynamic vehicle drive performance and energy efficiency, high power density ultra-capacitors are incorporated for fast charging and discharging during the regenerative braking and peak acceleration. This paper presents a comparative analysis between the UTS PHEV, a conventional series-parallel HEV and an ICE power vehicle powertrains using different drive cycles representing low and high congestion driving characteristics. It studies the fuel economy, AER, electrical consumption, operation cost and estimated total lifetime cost under a range of fuel prices for each vehicle.

\section{UTS PHEV CONFIGURATION AND VEHICLE PARAMETERS}

To perform a quantitative comparison in this study, a schematic representation of the UTS PHEV powertrain as illustrated in Figure 1 is modeled and simulated numerically in the MATLAB/SIMULINK environment. A detailed mathematical model of every component and the overall structure of the UTS PHEV powertrain can be referred to in [14]. By combining the constitutive equations of all components, we obtain a mathematical model of the overall structure of the UTS PHEV powertrain model as shown in Figure 2. The three powertrain configurations under consideration are: (1) conventional ICE, (2) series-parallel HEV, and (3) the proposed UTS PHEV. The vehicle type selected for the UTS PHEV is a five-passenger sedan, which is typical of the majority of passenger vehicles on the road [15]. 


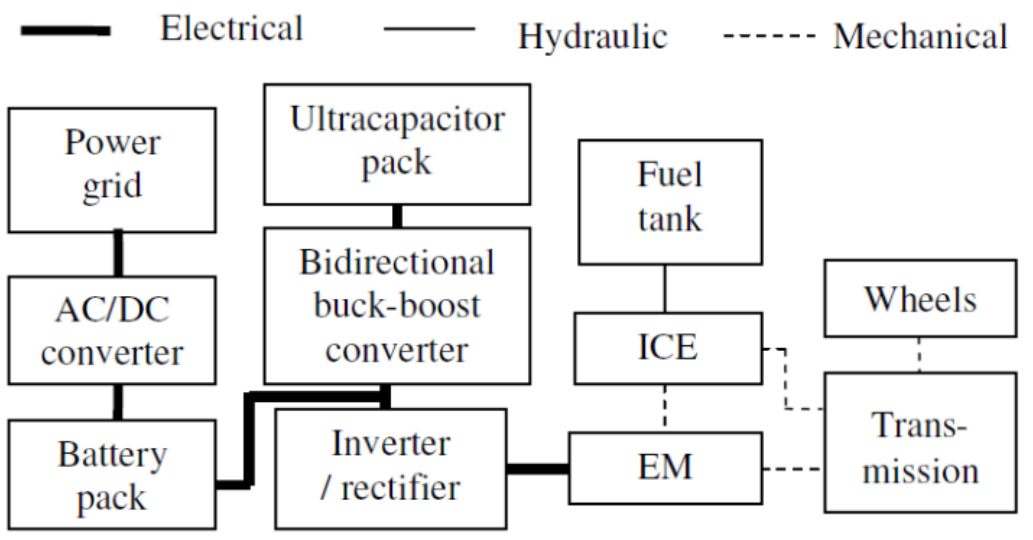

Figure 1. Schematic illustration of UTS PHEV powertrain.

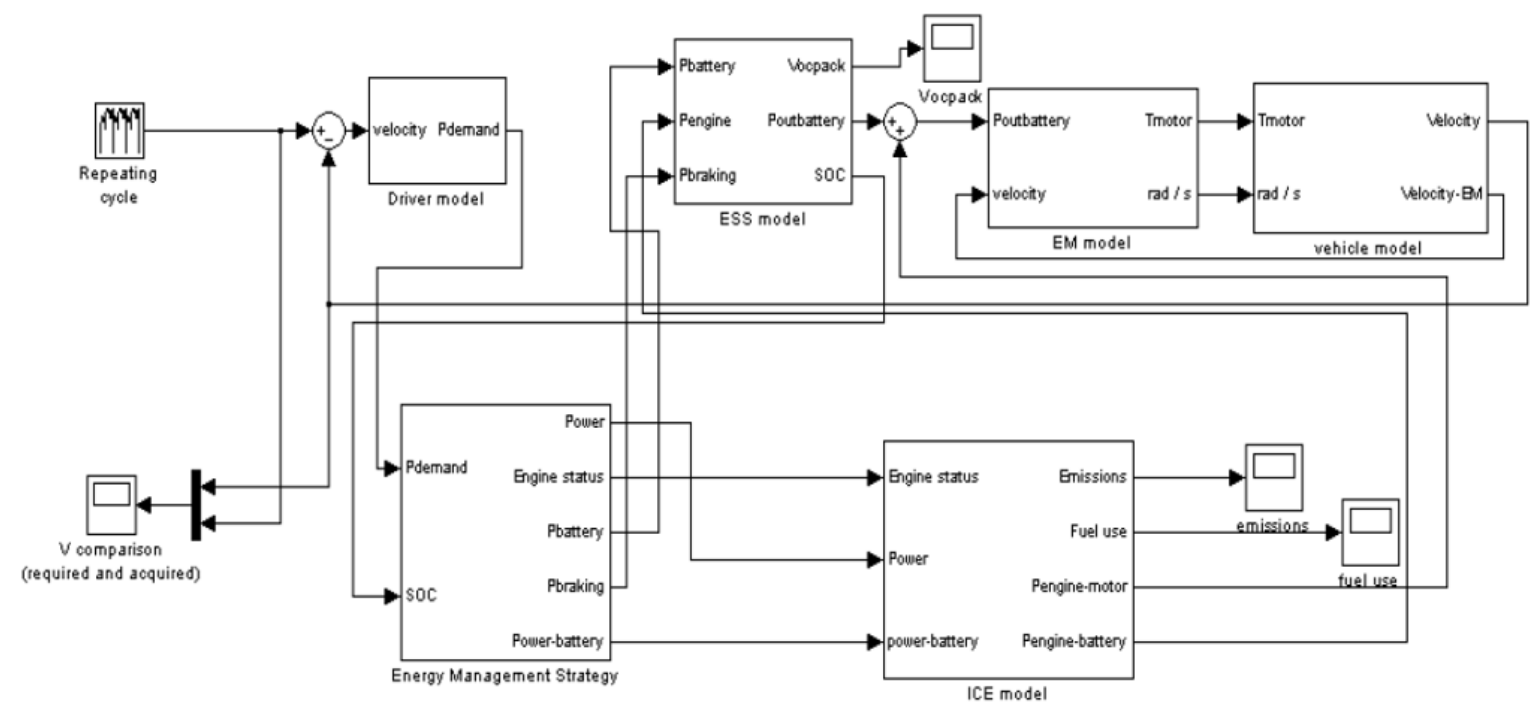

Figure 2. Overall powertrain structure of the UTS PHEV model in MATLAB/SIMULINK environment.

\section{UTS PHEV POWER SPLITTING DEVICE AND EMS DEVELOPMENT}

To meet its operational needs, apart from the control systems required for the EM and energy storage, the UTS PHEV powertrain requires an automatic transmission (AT) capable of providing various power propulsion modes, as well as varying the gear ratio between the ICE and the wheels and charging the battery bank whilst stopped. As with conventional powertrains, the ICE also has to operate within the region of high fuel efficiency and low emissions. The proposed transmission is based on the Ravigneaux planetary gear set without a torque converter to further reduce losses. It is shown in Figure 3. According to the power flow of the new 4-speed AT, as illustrated in Figure 4, there are six possible power propulsion modes, depending on the driver input, energy storage state of charge (SOC), and power demand for the vehicle. 


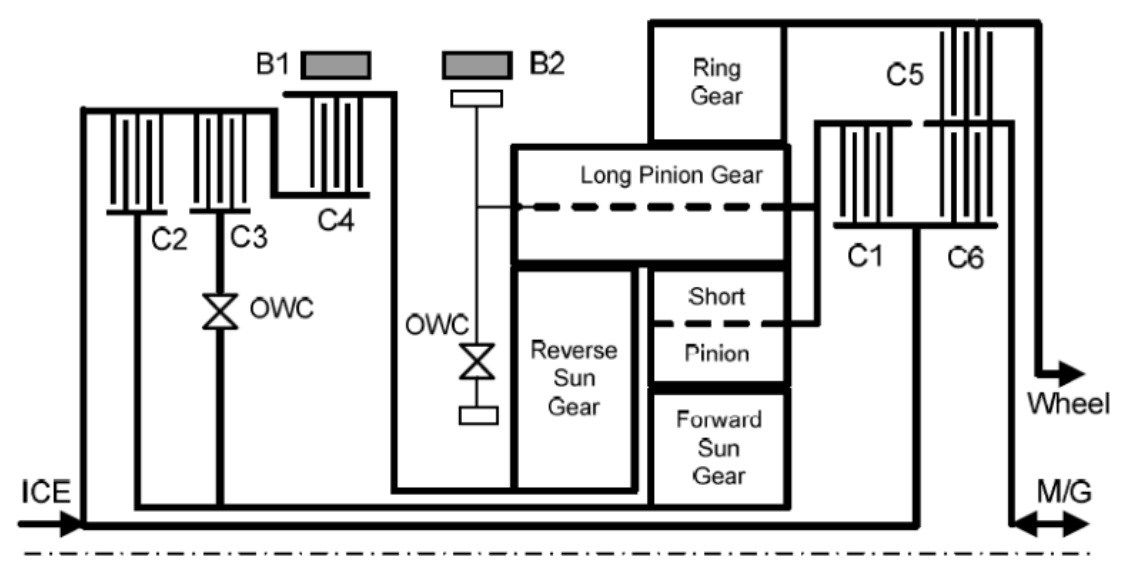

Figure 3. Power flow schematic of the new 4-speed AT without torque converter.

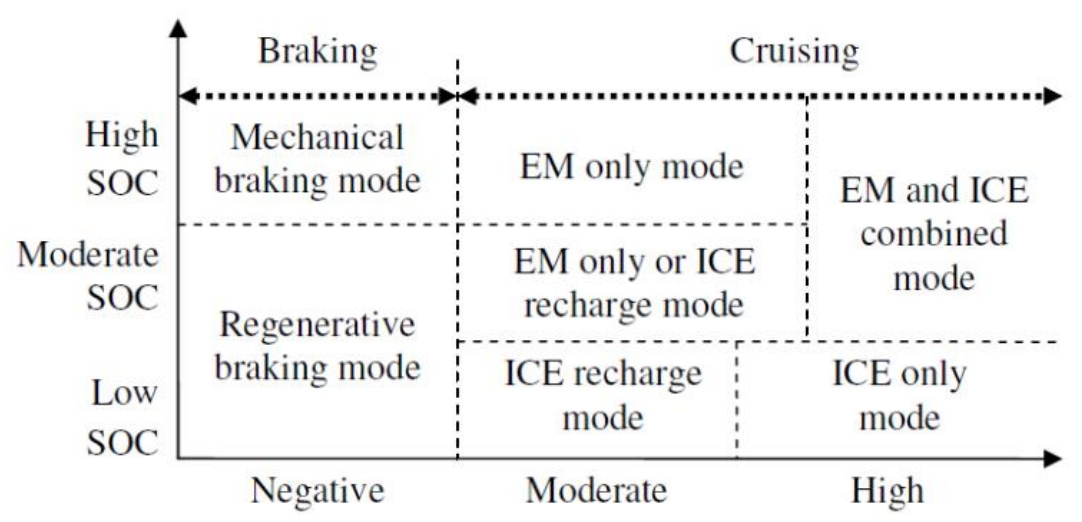

Figure 4. EMS modes of operation.

\section{DRIVE CYCLES}

\section{Proposed High and Low Congestion Drive Cycles}

The UTS PHEV powertrain model, series-parallel HEV and ICE-powered vehicle are numerically simulated in the MATLAB/SIMULINK environment for analysis of fuel economy, AER, electrical consumption, operation cost and total lifetime cost. For the low congestion cycle, as shown in Figure 5, the Highway Fuel Efficiency Test (HWFET), New European Drive Cycle (NEDC) and Urban Dynamometer Drive Schedule (UDDS) cycles are combined. This proposed cycle has a duration of $3320 \mathrm{~s}$, a range of $39.5 \mathrm{~km}$, and an average speed of $43 \mathrm{~km} / \mathrm{h}$. The high congestion drive cycle (see Figure 6) combines the Indian Urban Cycle (IUC), Indian City Cycle [16], and City Suburban Cycle (CSC) drive cycles. This high congestion cycle has a duration of 5352 seconds, a range of $39.9 \mathrm{~km}$, and an average speed of $27 \mathrm{~km} / \mathrm{h}$. The purpose of using cycles arranged in this method is to provide a more diverse set of driving conditions, where the driving cycles are not linked to a single method of development, reducing bias of the results to a particular drive cycle and developed in different traffic conditions. 


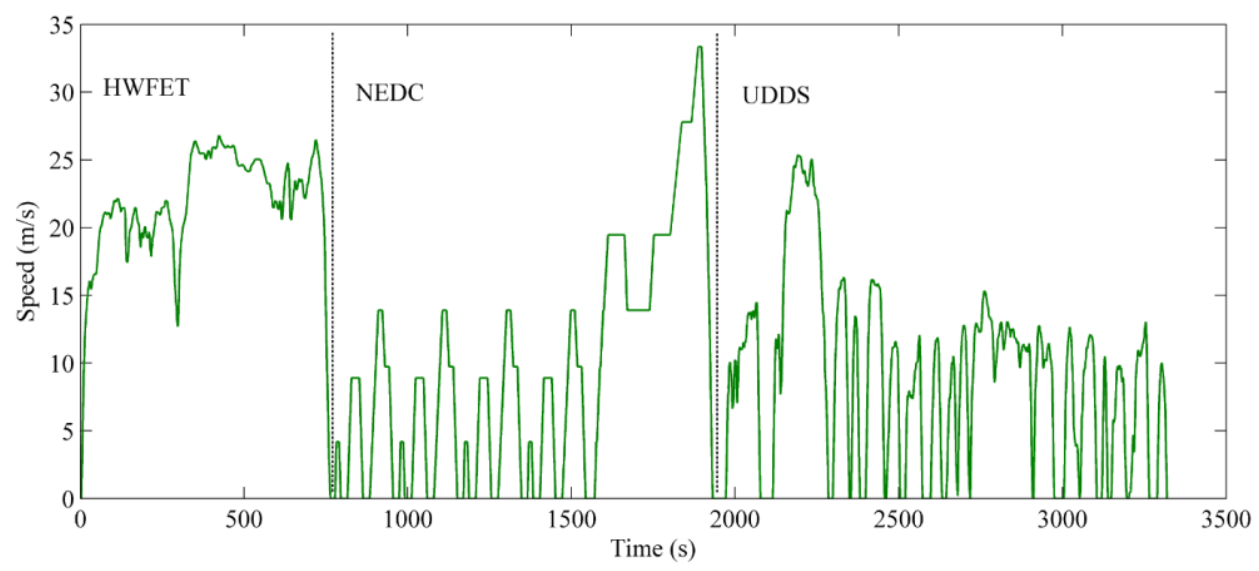

Figure 5. Low congestion driving characteristics drive cycle.

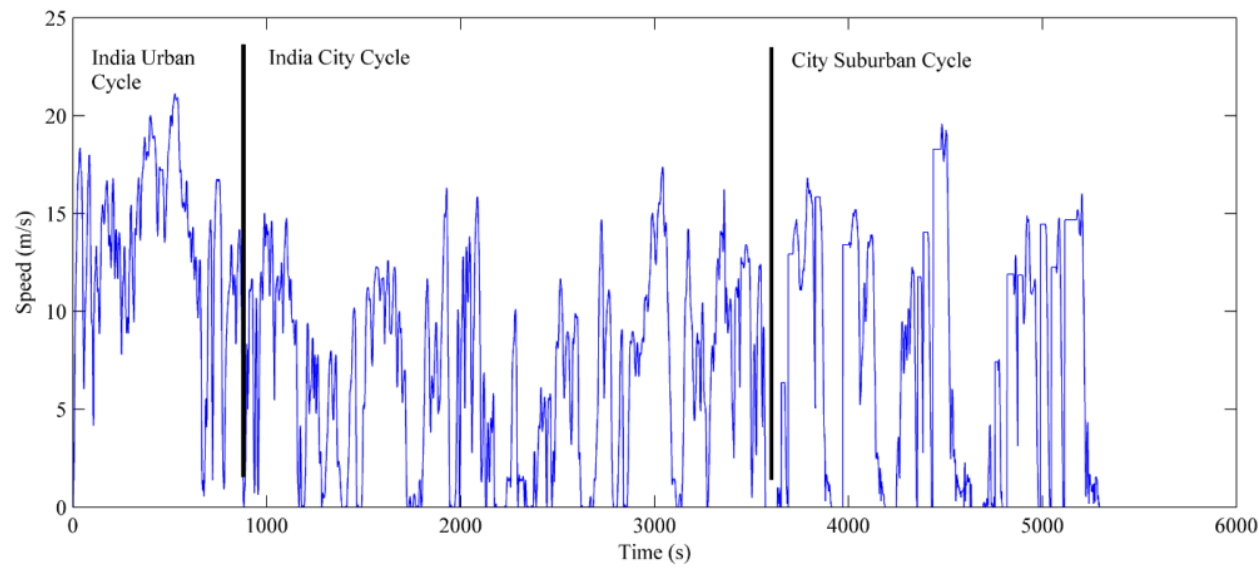

Figure 6. High congestion driving characteristics drive cycle.

\section{Test Methods}

For these analyses two types of fuel economy tests are employed, the partial charge test (PCT) and full charge test (FCT) [17]. If the ESS is fully charged, the fuel economy for a given range is calculated using the FCT method. In this method the equivalent energy stored in the battery as a volumetric ratio is considered along with the volume of fuel consumed.

$$
P C T=\frac{D}{V_{\text {fuel }}}
$$

where $D$ is the test distance in miles and $V_{\text {fuel }}$ is the volume of fuel consumed in gallons.

$$
F C T=D /\left(V_{\text {fuel }}+\frac{E_{\text {charge }}}{E_{\text {gasoline }}}\right)
$$

where $E_{\text {charge }}$ is the required electrical recharge energy in $\mathrm{kWh}$ and $E_{\text {gasoline }}$ is a constant equal to $8.83 \mathrm{kWh} / \mathrm{gal}$ representing the energy content in one liter of gasoline. 


\section{RESULTS AND DISCUSSION}

Simulations of each powertrain were conducted in the Simulink environment of Matlab for evaluation of the all-electric range, and fuel and electrical energy consumption. Table 1 lists the results for each of the compared vehicles during low and high congestion characteristic drive cycles using the PCT method to evaluate fuel consumption, whilst the AER is evaluated with the FCT only. The results of AER and electrical consumption highlight the differences in terms of congestion level between the different driving styles. The results demonstrate that the UTS PHEV achieves a higher AER and lower electrical consumption in the high congestion cycle, a result of the improved capability to capture regenerated energy during braking combined with a larger number of stop-start events. By contrast, the HEV configuration shows improved energy consumption with the low congestion cycle as a result of fewer acceleration demands. The results thus indicate that the capability to capture energy through regenerative braking is a significant source of energy gain when this process is maximized. Based on the fuel economy analysis results, the high congestion driving style of the UTS PHEV has lower fuel economy because more energy is required to repeatedly accelerate the vehicle. While the fuel economy of a conventional seriesparallel HEV and an ICE-powered vehicle is higher during low congestion driving characteristics, this is because the primary source of both powertrains is an ICE, and it is more efficient at high and constant vehicle speed.

Table 1. Vehicles' fuel economy, AER and electrical consumption.

\begin{tabular}{lllllll}
\hline Powertrain & \multicolumn{2}{c}{ UTS PHEV } & \multicolumn{2}{l}{$\begin{array}{l}\text { Conventional } \\
\text { series-parallel } \\
\text { HEV }\end{array}$} & \multicolumn{2}{l}{$\begin{array}{l}\text { ICE-powered } \\
\text { vehicle }\end{array}$} \\
\hline Drive cycle & Low & High & Low & High & Low & High \\
Fuel economy - mpg & 84 & 105 & 55 & 46 & 37 & 25 \\
Fuel economy - L/100 km & 2.8 & 2.2 & 4.3 & 5.1 & 6.3 & 9.4 \\
AER (km) & 49.9 & 58 & 12.9 & 8 & - & - \\
$\begin{array}{l}\text { Electrical consumption } \\
\text { (Wh/km) }\end{array}$ & 161.5 & 139.1 & 60.9 & 96.9 & - & - \\
\hline
\end{tabular}

According to the simulation results, the UTS PHEV powertrain has a significant improvement in the fuel economy, AER and electrical consumption for both driving style compared to a conventional HEV or ICE-powered vehicle. This is because the UTS PHEV powertrain has a larger ESS, which can support longer AER and uses less fuel to travel by optimizing the energy distribution from ESS, thereby reducing total emissions produced from the vehicle. At the same time, the UTS PHEV also gains advantage through employing ultra-capacitors, which can absorb a greater portion of regenerative braking energy and provide higher peak power during hard acceleration.

\section{ECONOMIC ANALYSIS OF DIFFERENT POWERTRAINS}

For further analysis of these different powertrain configurations, a comparative study on daily and annual operation costs was conducted over a distance of 40 miles $(64 \mathrm{~km})$ traveled under the developed low and high congestion characteristic drive cycles using the FCT method, resulting in an annual driving distance of 15,000 miles or about 24,000 
kilometers. This suggested daily trip is based on a return journey to work for the above average user, and this trip length is chosen primarily as it exceeds the AER of all vehicles, thereby necessitating fuel consumption of the PHEV. The assumptions used to generate the annual energy cost estimates were fuel and electricity costs of $\$ 0.66 /$ liter and $\$ 0.09 / \mathrm{kWh}$, respectively, consistent with information available in [18]. The daily and annualized operating costs for each powertrain are summarized in Table 2. Based on these results, it is demonstrated that both the hybrid vehicles are cheaper to run, as each is less dependent on fossil fuels. Furthermore, the PHEV uses a large quantity of stored electrical energy to drive the vehicle, further reducing costs. The PHEV can save about 33\% and 53\% annually for the low and high congestion driving characteristics drive cycles, compared to a conventional series-parallel HEV, and the annual operation cost saving of the UTS PHEV powertrain is around 56\% and 75\% compared to the ICEpowered vehicle. In order to measure a total lifetime cost for 10 years of ownership for each type of powertrain, it is necessary to include maintenance costs for different repair categories, such as oil, tire, transmission, ESS and miscellaneous costs based on respective lifetimes. This data is summarized in Table 3 . The purchase and annual maintenance cost as listed in Table 4 need to be included in the total lifetime cost calculation in order to obtain a reasonable and practical estimated lifetime cost.

Table 2. Vehicles' daily and annual operation cost under same distance.

\begin{tabular}{|c|c|c|c|c|c|c|}
\hline \multirow{2}{*}{$\begin{array}{l}\text { Powertrain } \\
\text { Drive cycle }\end{array}$} & \multicolumn{2}{|c|}{ UTS PHEV } & \multicolumn{2}{|c|}{$\begin{array}{l}\text { Conventional } \\
\text { series-parallel } \\
\text { HEV }\end{array}$} & \multicolumn{2}{|c|}{$\begin{array}{l}\text { ICE-powered } \\
\text { vehicle }\end{array}$} \\
\hline & Low & High & Low & High & Low & High \\
\hline Fuel used (gallon) & 0.19 & 0.11 & 0.72 & 0.85 & 1.08 & 1.60 \\
\hline $\begin{array}{l}\text { Electrical energy used } \\
(\mathrm{kWh})\end{array}$ & 8.064 & 8.064 & 0.780 & 0.780 & - & - \\
\hline Daily fuel cost $(\$)$ & 0.48 & 0.28 & 1.80 & 2.13 & 2.70 & 4.00 \\
\hline Daily electricity cost (\$) & 0.73 & 0.73 & - & - & - & - \\
\hline Daily operation cost (\$) & 1.20 & 1.01 & 1.80 & 2.13 & 2.70 & 4.00 \\
\hline Annual fuel cost $(\$)$ & 176.25 & 105.00 & 675.00 & 798.75 & 1012.50 & 1500.00 \\
\hline Annual electricity cost (\$) & 273.75 & 273.75 & - & - & - & - \\
\hline Annual operation cost $(\$)$ & 450.00 & 378.75 & 675.00 & 798.75 & 1012.50 & 1500.00 \\
\hline
\end{tabular}

Figure 7 shows the total cost breakdown for each vehicle configuration over the same range of fuel costs. The dominant variable demonstrated in each of these figures (Figure 7(a)-(d)) is solely that of fuel, and the higher fuel consumption of the ICEpowered vehicle significantly increases overall costs to the extent that, at the highest projected fuel price, this cost represents more than $50 \%$ of all the costs of ownership of this type of vehicle. For the PHEV and HEV, fuel costs are approximately $10 \%$ and $30 \%$ of total vehicle costs, respectively. At the lower cost end of the fuel prices, these costs are significantly less dominant for the ICE vehicle at about $36 \%$, while the PHEV fuel cost is $8 \%$. This results from the PHEV relying on grid source electricity as the primary driving energy source. 
Table 3. Estimated maintenance cost for different repair categories.

\begin{tabular}{llll}
\hline Powertrain & UTS PHEV & $\begin{array}{l}\text { Conventional series- } \\
\text { parallel HEV }\end{array}$ & ICE-powered vehicle \\
\hline Oil & $\$ 50.00 / 5000$ miles & $\$ 50.00 / 5000$ miles & $\$ 50.00 / 3000$ miles \\
Tire & $\$ 440.00 / 60000$ & $\$ 440.00 / 60000$ & $\$ 440.00 / 60000$ \\
& miles & miles & miles \\
Transmission & $\$ 2000.00 / 10$ years & $\$ 2000.00 / 10$ years & $\$ 2000.00 / 10$ years \\
ESS & $\$ 7500.00 / 10$ years & $\$ 6450.00 / 10$ years & $\$ 120.00 / 4$ years \\
Miscellaneous & $\$ 300.00 /$ year & $\$ 300.00 /$ year & $\$ 300.00 /$ year \\
\hline
\end{tabular}

Table 4. Purchase and annual maintenance estimated costs.

\begin{tabular}{llll}
\hline Powertrain & $\begin{array}{l}\text { UTS } \\
\text { PHEV }\end{array}$ & $\begin{array}{l}\text { Conventional } \\
\text { series- } \\
\text { parallel HEV }\end{array}$ & $\begin{array}{l}\text { ICE- } \\
\text { powered } \\
\text { vehicle }\end{array}$ \\
\hline Purchase cost $(\$)$ & 28000.00 & 25000.00 & 18000.00 \\
Annual oil cost $(\$)$ & 150.00 & 150.00 & 250.00 \\
Annual tire cost $(\$)$ & 110.00 & 110.00 & 110.00 \\
Annual transmission cost $(\$)$ & 200.00 & 200.00 & 200.00 \\
Annual ESS cost $(\$)$ & 750.00 & 645.00 & 30.00 \\
Miscellaneous cost $(\$)$ & 300.00 & 300.00 & 300.00 \\
Total annual maintenance estimated cost $(\$)$ & 1510.00 & 1405.00 & 890.00 \\
\hline
\end{tabular}
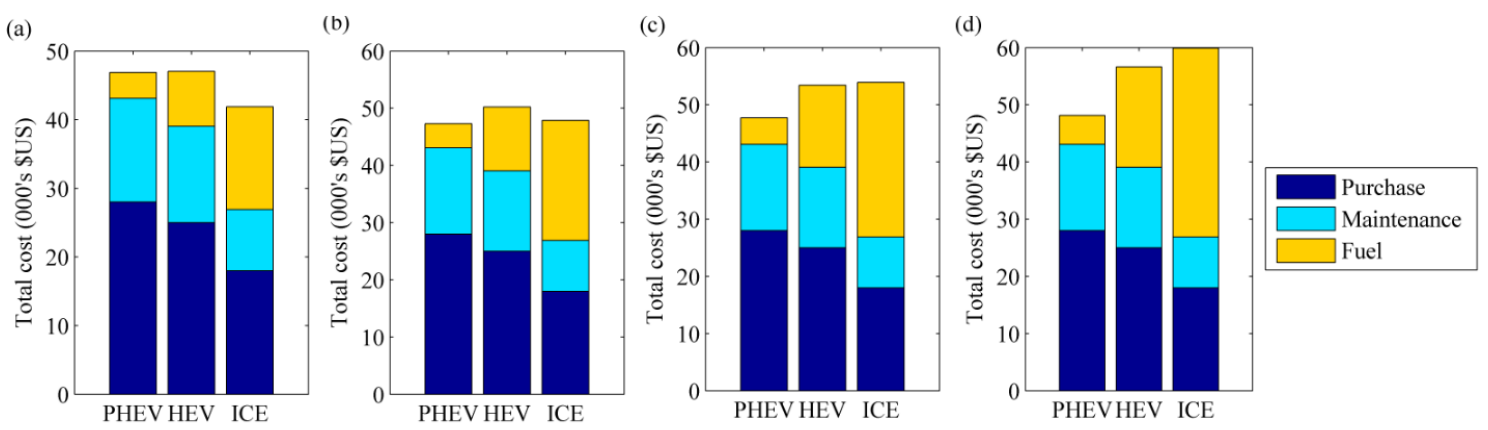

Figure 7. Breakdown of total costs for each vehicle type over 10-year lifecycle: (a) \$US 0.66/liter (\$US 2.50/gallon), (b) \$US 0.99/liter (\$US 3.50/gallon), (c) \$US 1.19/liter (\$US 4.50/gallon), and (d) \$US 1.45/liter (\$US 5.50/gallon).

\section{CONCLUSIONS}

Comparing the simulation results of fuel economy, AER and electrical consumption of the UTS PHEV powertrain subject to different drive cycles, one can readily conclude that there are benefits in terms of both reduced fuel use and energy recovered, where increased braking frequency and the application of an ultra-capacitor bank produces a higher degree of energy recovery. Furthermore, the main drive power of the UTS PHEV powertrain comes from the electric motor supplied by the battery bank; however, the ICE is needed as an auxiliary power source. Adding the ultra-capacitor bank in this powertrain can more effectively capture the regenerative braking energy, resulting in better energy efficiency, and meet the large power demand from the motor, resulting in 
better dynamic drive performance. Cost-based analysis of the purchase, maintenance, and ongoing fuel and electricity consumption over a 10-year lifespan of the vehicle has been used to demonstrate the trade-off resulting from a higher upfront cost for the PHEV and HEV. These results demonstrate that, depending on the average price per liter of fuel, there can be long-term cost savings achieved through the use of PHEVs or HEVs. The most volatile cost of \$US/liter price of fuel was deliberately chosen as the only variable to evaluate how this alone impacts on the overall lifetime costs of each vehicle.

\section{ACKNOWLEDGEMENTS}

The financial support of this work by the Australian Research Council (DP1096847), the University of Technology, Sydney and the Universiti Malaysia Terengganu, is gratefully acknowledged.

\section{REFERENCES}

[1] Niasar AH, Moghbelli H, Vahedi A. Design methodology of drive train for a series-parallel hybrid electric vehicle (SP-HEV) and its power flow control strategy. IEEE International Conference on Electric Machines and Drives. 2005; 1549-54.

[2] Chan CC. The state of the art of electric and hybrid vehicles. Proceedings of the IEEE. 2002;90:247-75.

[3] Ehsani M, Gao Y, Miller JM. Hybrid electric vehicles: architecture and motor drives. Proceedings of the IEEE. 2007;95:719-28.

[4] Rahmat MS, Ahmad F, Mat Yamin AK, Aparow VR, Tamaldin N. Modeling and torque tracking control of permanent magnet synchronous motor (PMSM) for hybrid electric vehicle. International Journal of Automotive and Mechanical Engineering. 2013;7:955-67.

[5] Salleh I, Md. Zain MZ, Raja Hamzah RI. Evaluation of annoyance and suitability of a back-up warning sound for electric vehicles. International Journal of Automotive and Mechanical Engineering. 2013;8:1267-77.

[6] Jinrui N, Zhifu W, Qinglian R. Simulation and Analysis of Performance of a Pure Electric Vehicle with a Super-capacitor.Vehicle Power and Propulsion Conference. 2006; 1-6.

[7] Baisden AC, Emadi A. ADVISOR-based model of a battery and an ultracapacitor energy source for hybrid electric vehicles. IEEE Transactions on Vehicular Technology. 2004;53:199-205.

[8] Chan CC, Bouscayrol A, Chen K. Electric, hybrid, and fuel-cell vehicles: Architectures and modeling. IEEE Transactions on Vehicular Technology. 2010;59:589-98.

[9] Liu J, Peng H. Modeling and control of a power-split hybrid vehicle. IEEE Transactions on Control Systems Technology. 2008;16:1242-51.

[10] Wu X, Cao B, Li X, Xu J, Ren X. Component sizing optimization of plug-in hybrid electric vehicles. Applied Energy. 2011;88:799-804.

[11] Walker P, Rahman SA, Zhang N, Zhan W, Lin Y, Zhu B. Modelling and simulation of a two speed electric vehicle. Sustainable Automotive Technologies. 2012; 193-8. 
[12] Abdul Rahman S, Zhang N, Zhu J. A Comparative Analysis of Fuel Economy and Emissions between a Conventional HEV and the UTS PHEV. 2011.

[13] Rahman SA. Optimal power management for the UTS plug-in hybrid electric vehicle: Sydney, Australia: University of Technology; 2011.

[14] Wang Z, Li W, Xu Y. A novel power control strategy of series hybrid electric vehicle. IEEE/RSJ International Conference on Intelligent Robots and Systems. 2007; 96-102.

[15] Markel T, Wipke K. Modeling grid-connected hybrid electric vehicles using ADVISOR. The Sixteenth Annual Battery Conference on Applications and Advances, 2001; 23-9.

[16] Sgriccia N, Hawley MC, Misra M. Characterization of natural fiber surfaces and natural fiber composites. Composites Part A: Applied Science and Manufacturing. 2008;39:1632-7.

[17] Gonder J, Simpson A. Measuring and reporting fuel economy of plug-in hybrid electric vehicles: National Renewable Energy Laboratory; 2006.

[18] Graham R. Comparing the benefits and impacts of hybrid electric vehicle options. Electric Power Research Institute (EPRI), Palo Alto, CA, Report. $2001 ; 1000349$. 